\title{
Correction to: Diurnal variations in sulfur transformations at the chemocline of a stratified freshwater lake
}

\author{
Khoren Avetisyan · Werner Eckert • Alyssa J. Findlay (D) Alexey Kamyshny Jr. (D)
}

Published online: 28 October 2019

(C) Springer Nature Switzerland AG 2019

Correction to: Biogeochemistry

https://doi.org/10.1007/s10533-019-00601-5

In the initial online version of the article, the sampling station location "F" was missing in Fig. 1. The original article has been corrected.

Publisher's Note Springer Nature remains neutral with regard to jurisdictional claims in published maps and institutional affiliations.

The original article can be found online at https:// doi.org/10.1007/s10533-019-00601-5.

K. Avetisyan · A. J. Findlay · A. Kamyshny Jr. ( $₫)$ Department of Geological and Environmental Sciences, Faculty of Natural Sciences, Ben-Gurion University of the Negev, P.O. Box 653, 84105 Beer Sheva, Israel e-mail: alexey93@gmail.com

W. Eckert Israel Oceanographic \& Limnological Research Ltd., Yigal Allon Kinneret Limnological Laboratory,

P.O. Box 447, 14950 Migdal, Israel

\section{A. J. Findlay}

Department of Bioscience, Center for Geomicrobiology, Aarhus University, Aarhus, Denmark 